УДК 801.731

ББК 83

DOI 10.22455/2619-0311-2019-4-209-215

Татьяна Ковалевская

\begin{abstract}
Рецензия на книгу Т.А. Касаткиной «Достоевский как философ и богослов: художественный способ высказывания» (М: Водолей, 2019. 336 с.)
\end{abstract}

Tatyana Kovalevskaya

\title{
T.A. Kasatkina. Dostoevsky as a Philosopher and Theologian: Artistic Method of Speaking (Moscow: Vodoley, Publ., 2019. 336 p.). Review
}

Об авторе: Татьяна Вячеславовна Ковалевская, доктор филос. наук, доцент, профессор кафедры иностранных языков ФМОиЗР ИАИ, Российский государственный гуманитарный университет (Москва).

E-mail: tkowalewska@yandex.ru

Для цитирования: Ковалевская Т.В. Рецензия на книгу Т.А. Касаткиной «Достоевский как философ и богослов: художественный способ высказывания» // Достоевский и мировая культура. Филологический журнал. 2019. № 4(8). C. 209-215

DOI 10.22455/2619-0311-2019-4-209-215

About the author: Tatyana V. Kovalevskaya, Doctor of Philosophical Sciences, Docent, Full Professor, Foreign Languages Department of the School of International Relations and Regional Studies, Institute for History and Archives, Russian State University for the Humanities (Moscow).

E-mail: tkowalewska@yandex.ru

For citation: Kovalevskaya T.V. T.A. Kasatkina. Dostoevsky as a Philosopher and Theologian: Artistic Method of Speaking. Review. Dostoevsky and World Culture, Philological journal, 2019, No 4(8), pp. 209-215

DOI 10.22455/2619-0311-2019-4-209-215 
Книга Т.А. Касаткиной состоит из трех частей: «Методология анализа и интерпретации художественного текста», «"Записки из подполья” как христианский текст» и «Художественные тексты “Дневника писателя” . Каждая часть, в свою очередь, подразделяется на ряд глав и подглав, и эта система детально описывает процесс движения мысли автора.

Это очень необычная книга. Необычна она, во-первых, уже тем, какое солидное место отводится объяснению теоретических оснований работы - первая часть занимает практически треть книги.

Еще более необычна она, во-вторых, тем, что теория чтения представлена как взаимоотношение двух равных личностей, двух субъектов, и, собственно, первая глава первой части так и называется: «О субъект-субъектном методе чтения». «Главным инструментом субъект-субъектного метода является сама личность исследователя, вольно умаляющаяся перед познаваемым для того, чтобы не исказить и не экранировать передаваемое ей таким образом знание - и одновременно расширяющаяся для того, чтобы мочь взаимодействовать с открывающимся целым в максимально широком диапазоне, предоставлять исследуемому максимально доступную исследователю шкалу» (с.12).

B-третьих, книга неожиданна и замечательна тем, что предназначена не только для академического сообщества, но и для сообщества преподавательского и обучающегося. В этом отношении книга принципиально важна для зачастую замкнутой в себе научной среды, чьи труды нередко остаются заключенными в рамках сугубо академической аудитории, в лучшем случае выходя за ее пределы в списках литературы в курсовых, выпускных квалификационных и диссертационных работах, а по сути, оставаясь все в той же «башне из слоновой кости».

Такое положение дел плохо не только потому, что создает у людей, не включенных в сферу гуманитарных наук, впечатление об их бесполезности и ненужности. Это плохо прежде всего потому, что не соответствует духу и смыслу классической литературы (не только русской, но русской прежде всего, занимающей в культуре место целого спектра наук от философии до социологии, культурологии и даже богословия), направленной прежде всего на взаимодействие с личностью читателей, а не, в отличие, например, 
от играющей с читателями литературы постмодернизма, на игру в шарады с их интеллектом. Субъект-субъектное чтение, по мнению T.А. Касаткиной, имеет тектонические последствия: «В результате взаимодействия в процессе такого познания на каждом новом витке герменевтического круга меняется не только видение соотношения общего и частностей в познаваемом - но меняется и сама личность исследователя» (с.12).

В этом отношении книга Т.А. Касаткиной конгениальна и принципиально важной черте творчества именно Достоевского - признания за читателем такой же субъектности, какой обладает автор. Но в признании взаимной субъектности принципиально подчеркивается несовпадение с традиционной интерпретацией знаменитой формулы Барта «Автор умер», из которой, неважно уже, по воле автора этой сентенции или вопреки ей, возникло представление о том, что всякий смысл в литературное произведение вносит читатель, и только он. Ключевое значение в рецензируемой книге имеет именно сохранение субъектности как автора, так и читателя.

Во многом книга противостоит текущим принципам анализа, например, в ней утверждается возможность стопроцентного понимания авторского замысла. «...[Ч]итатель, прочтя роман, совершенно так же понимает мысль писателя, как сам писатель понимал ее, создавая свое произведение», - писал Достоевский (цитируется на с. 33), и его высказывание становится пределом исследования художественного текста. И хотя книге свойственна некая жесткость формулировок, она неизбежна при той задаче, которую ставит себе автор - стремиться именно к этому пределу понимания. Эта способность, словно бы незаметно, идти против, казалось бы, ключевых установок современного литературоведения потому, что они не соответствуют той художественной стихии, с которой встречается исследователь - еще одно из многочисленных достоинств книги, где чтение и исследовательская работа идут не так, как принято, а так, как до́лжно, потому, что именно такое чтение предполагал для своих произведений Достоевский.

Задача максимального понимания также ставится в той системе координат, в какой писал сам Достоевский - в принципиально христианской системе координат, что также важно в современной культуре, которую часто именуют «пост-христианской». Такой взгляд на 
автора и читателя вряд ли возможен в иной системе представлений, на какую бы степень гуманизма она ни претендовала, и в этом автор также в глубинных основаниях своей работы принципиально конгениален той личности, с которой встречается в ходе чтения и исследования. Казалось бы, об этом можно и не писать, но, после столкновений и в исследовательском, и в преподавательском опыте с последовательной антирелигиозностью значительной части современной науки (без всякого реального уважения к личности исследуемых авторов, будь они хоть трижды христианами, при том что декларируется уважение ко всему спектру взглядов), уже невозможно не обратить внимание на то, что в этой книге Достоевский программно читается как христианский автор, а его произведения как тексты христианские. В книге, обращенной и к обучающимся, это крайне важное измерение. Уважение к субъектности не предполагает отказа от должного ради этого уважения.

Понимание Достоевского как писателя христианского вкупе с преобразующей природой чтения его произведений очень важны еще в одном аспекте. Ранее говорилось о том, что книга Т.А. Касаткиной помогает увидеть значимость гуманитарных наук. Но некоторые гуманитарные науки, например филология, представляют собой в значительной степени (если не исключительно) «надстройку» над своей основой, в данном случае литературой, а один из сегодняшних вопросов часто ставится так: «А нужна ли нам вообще классическая литература?». Этот вопрос можно возмущенно отмести, нелестно охарактеризовав умственные способности и уровень развития задающего его человека, но такая реакция только покажет, что осмысленного ответа нет и укрепит сомневающегося в его сомнениях. Потому что если мы читаем литературу исключительно как порождение социально-исторических условий конкретной эпохи и воплощение этих самых условий в художественных образах, то, кроме музейного, никакого иного интереса такая литература представлять не может и не может иметь никакой насущности для читателей, живущих в других исторических контекстах. Но метафизическое прочтение литературы делает ее актуальной для людей всех эпох. Мы читаем Достоевского не потому, что подпольный человек - порождение 1840-х годов, а нам интересно, какие были эти годы, хотя нас с ними лично и эмоционально практически ничего не связывает. Мы читаем 
Достоевского потому, что «Записки из подполья» показывают нам смысл человеческого бытия на земле в любое время, безотносительно исторических условий, влияющих только на конкретные формы проявления вечных общечеловеческих устремлений. Приходя к ученикам с текстом Достоевского, книга помогает им увидеть ответ, который давал Достоевский на вопрос «Зачем живет человек?».

Обращенность к обучающимся (пусть это слово несколько казенное, но я не хочу писать «школьники» или «студенты», потому что читать эту книгу могут все) описывается во второй главе первой части: «Организация совместной научной и учебной работы в рамках субъект-субъектного метода: увеличение мерностей герменевтического круга». И эта работа также субъектна - за обучающимися признается та же субъектность, что и за автором, и за исследователем, совместную работу организующим. Однако здесь важно то, что, признавая субъектность, автор не приравнивает ее к субъективности, что часто происходит, когда в работе с учащимися преподаватель выбирает себе роль только модератора высказываний, не основанных ни на чем, кроме субъективности ученика.

Может показаться, что в рецензии непропорционально большое место уделяется теоретическим основаниям исследования, тогда как необходимо сказать о ее междисциплинарности (иконопись, живопись, богословие входят в ткань текста как его неотъемлемая часть), о том, как личные записи и неоконченная публицистика естественно входят в контекст истолкования художественного текста (запись «Маша лежит на столе...» и заметки к незавершенной статье «Социализм и христианство» становятся существенно необходимым контекстом понимания «Записок из подполья»), об описании элементов богословско-философского языка Достоевского (анализ понятия «личность» у писателя), о блестящем прочтении анализируемых текстов, но для меня очень важным в этой книге представляются не только богословско-философское прочтение прежде всего «Записок из подполья», но именно первоначальное представление этого анализа в теоретических категориях, что особенно ярко и наглядно дает представление не только об используемой собственно автором методологии, но и о всей значимости гуманитарных наук и, что еще важнее, литературы как таковой, которые способствуют развитию того преображения человеческой личности, которому посвящено 
все творчество Достоевского, и дают ответы на фундаментальные вопросы человеческого бытия.

Жанр рецензии предполагает традиционное перечисление достоинств, за которым следует столь же традиционное перечисление недостатков. В своей рецензии я нарушу эту традицию, потому что под недостатками я понимаю наличие фактических ошибок, противоречие в логике текста, намеренные опущения фактов, не укладывающихся в канву работы, чего здесь нет. Мне интересно было бы увидеть имя М.М. Бахтина не только в контексте анализа «Записок из подполья», но и в контексте теоретической части книги, потому что его теория полифонического романа, возможно, не менее статьи Р. Барта повлияла на развитие представлений о смерти всякого автора и господстве субъективности читателя (и уже неважно, соответствовало ли это взглядам самого Бахтина). Но объем книги ограничен, а интересы рецензентов не являются критериями оценки рецензируемого текста.

Книга Т.А. Касаткиной представляет очень важный вклад как в исследование творчества Ф.М. Достоевского, так и в теорию литературоведения и педагогики. В этом, как и в сфере охваченных в ней тем, она отвечает современным требованиям междисциплинарности исследований. Одновременно эта книга служит тому, чтобы вернуть гуманитарные науки в сферу «гуманитарности», то есть понимания их сущностной важности как для существования, так и для бытия человека. 


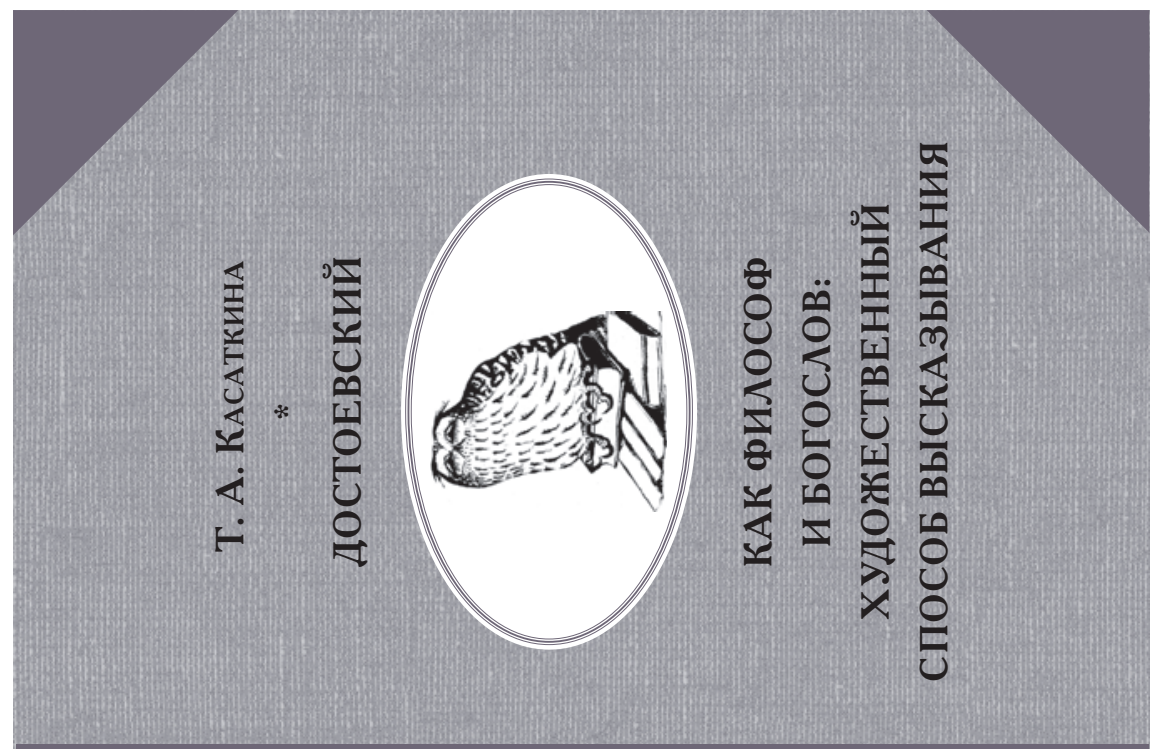

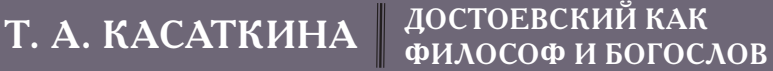
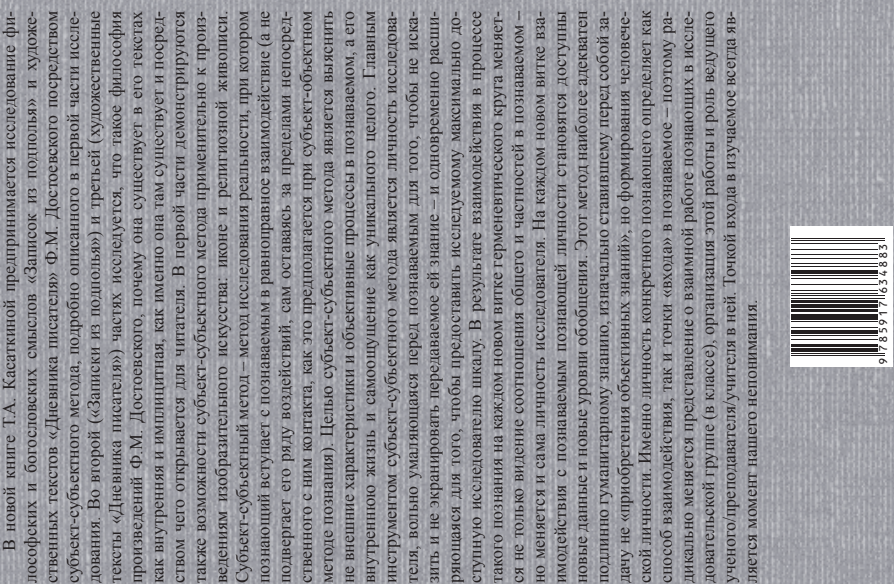